\title{
La recuperación económica poscrisis en Tailandia
}

$\mathbf{I}_{\mathrm{t}}^{\mathrm{n}}$ ntroducción del siglo XX (sobre todo el bienio 1997-1998) volvieron a asombrar al mundo, como en 19941995 cuando la crisis económica mexicana tuvo un impacto en la economía regional y mundial. Nuevamente, al igual que sucedió con México, los principales organismos económicos internacionales y los estudiosos de las economías de la región asiática del Pacífico fueron sorprendidos, debido a que en esta región, y en particular en Tailandia, dio inicio en 1997 la crisis financiera asiática.

Aunque tal crisis no afectó a todos los países de la región por igual, sí impactó a algunos de los más importantes, particularmente, a los máximos exponentes del otrora exitoso modelo asiático, con sus exportaciones intensivas en trabajo y de baja tecnología, como motor del crecimiento y desarrollo (Robins 2000). Tailandia, Taiwán, Corea del Sur, Singapur, Malasia, Filipinas y recientemente Hong Kong (antes de ser considerada la quinta región autónoma especial de China continental) sufrieron los efectos de una estrategia de desarrollo, que se vio trastocada por las insuficiencias del modelo de acumulación del capital a escala internacional y de los efectos perniciosos de una política económica laxa, que generó contradicciones entre las principales variables de la economía (González y Segura 2001).

Cada uno de estos países trató de resolver de la mejor manera los efectos económicos resultantes del colapso, cuyo resultado inmediato fue la devaluación de las principales monedas y el desequilibrio económico fundamental. Tailandia, hacia el año 2000, registró tasas de crecimiento del PIB cercanas

* Investigador del Centro Universitario de Investigaciones sobre la Cuenca del Pacífico de la Universidad de Colima. a 5 por ciento y contrarrestó y, en algunos casos, hizo cambiar de signo a algunas de las más importantes variables macroeconómicas colapsadas.

En este breve escrito describiremos las acciones que en materia de política económica tomó Tailandia para responder a la crisis financiera, resaltando al sector o agentes económicos sobre los que ha recaído el costo de la incipiente recuperación económica. Es decir, no nos abocaremos a la explicación de la crisis, pues, por las medidas que aplicó Tailandia (más de manera obligada que voluntaria), la interpretación finalmente aceptada fue la del Fondo Monetario Internacional (FMI 1998) y del Banco Mundial (BM 1998). Sostendremos, como Krugman (1999), que, más que explicada por las recetas tradicionales del organismo, ${ }^{1}$ dicha recuperación se debe al principio de aceleración de la demanda derivada ${ }^{2}$ posterior a una crisis $y$, que en cambio, surgieron y permanecen otros efectos económico-sociales adheridos a la aplicación de las recomendaciones de política económica por parte del FMI.

\section{La crisis financiera y ayuda del FMI}

La crisis financiera de Tailandia, de acuerdo con Cheah (2000), se manifestó en la economía real con caídas de la producción, cierre de empresas, incremento de la deuda externa, incertidumbre, caída de consumo, desempleo, disminución de reservas internacionales, incremento de la tasa de cambio, aumento de las tasas de interés, etcétera; es decir, las manifestaciones típicas de un fenómeno de esa naturaleza (ver cuadro siguiente).

El gobierno de Tailandia, con recursos económicos insuficientes para hacer frente a una situación de esa naturaleza, acudió al prestamista de última instancia internacional, el FMI, para amortiguar los efectos inmediatos de la crisis. El organismo, representante máximo 
La recuperación económica poscrisis en Tailandia

Cuadro 1

Tailandia, principales variables macroeconómicas, 1994-1997

\begin{tabular}{lrrrr}
\hline Rubro & 1994 & 1995 & 1996 & 1997 \\
PIB. Tasa de crecimiento anual (\%) & 8.9 & 8.8 & 5.9 & -1.4 \\
PIB- per cápita (en miles de bahts) & 60,903 & 70,583 & 77,043 & 78,219 \\
Consumo total. Tasa de crecimiento anual (\%) & 7.9 & 7.3 & 7.5 & -1.3 \\
Inversión en activos fijos (\% PIB) & 40.3 & 41.6 & 41.7 & 35 \\
Reservas internacionales (miles de millones de & 30.3 & 37 & 38.7 & 24.5 \\
dólares) & & & & \\
Deuda externa (miles de millones de dólares) & 64.86 & 82.56 & 90.53 & 109.3 \\
Tipo de cambio (baht/dólar de Estados Unidos) & 25.1 & 24.9 & 25.34 & $39.3 *$ \\
Tasa de interés & 8.12 & 11.1 & 13.15 & 15.25 \\
Empleo (millones de personas) & 30.16 & 30.82 & 31.22 & 31.64 \\
Salario mínimo (baht por día)* & 135 & 145 & 157 & 157 \\
Balanza de cuenta corriente (\%PIB) & -5.6 & -8 & -7.9 & -2 \\
* Para Bangkok y las provincias de Samut Prakan, Nonthaburi, Pathum Thani, Nakhon Athom, Samut Sakhon y Phuket. & & & &
\end{tabular}

de la ortodoxia neoliberal, sugirió un programa de ajuste económico que pasaba por las recomendaciones-condiciones exigidas a todos los países con problemas en la cuenta corriente de la balanza de pagos. Dicho paquete de apoyo finalmente quedó constituido por las aportaciones del FMI, el Banco Mundial y el Banco Asiático de Desarrollo (Japón, principalmente) que, en conjunto, desembolsarían $\$ 17.2$ miles de millones de dólares y quedó concluido en junio de 2000, con la utilización de $\$ 14.3$ miles de millones de dólares por parte de Tailandia.

En efecto, el organismo diseñó un paquete de ayuda financiera, semejante al decálogo del Consenso de Washington (Banco Mundial 1998) que exigía realizar un ajuste global del sistema económico para estabilizar la economía y restituir la confianza de la comunidad internacional. Los rasgos fundamentales del programa de ajuste fueron los siguientes: ${ }^{3}$

- reforma estructural al sistema financiero para restablecer la confianza exterior y restituir los flujos de capitales

- control del crédito y elevación de las tasas de interés

- políticas económicas de ajuste para facilitar la carga al sector privado debido a la salida de capitales

- restitución de las reservas internacionales
- reducción del gasto público en alrededor de 3 por ciento del PIB e incremento del nivel de impuestos

- flotación del tipo de cambio y determinación por el mercado

- mayor liberalización comercial

- balancear al sector público mediante reducción del déficit de la cuenta corriente. $^{4}$

Como se observa, las medidas "sugeridas" fueron idénticas a las aplicadas por las economías de América Latina a inicios de la década de los ochenta y fechas posteriores, cuyo efecto último ha sido la contracción de la actividad económica, la disminución de la demanda efectiva, el descenso continuo del bienestar económico-social y la dependencia absoluta del FMI para la determinación de la política económica interna.

En la siguiente sección se analizan algunos de los efectos macroeconómicos y sociales que ha registrado Tailandia como resultado de la aplicación de la política económica neoliberal.

Efectos económicos y sociales de la aplicación de la política económica de ajuste, 1998-2001.

Con la aplicación de las medidas de ajuste impuestas por el FMI en Tailandia, que no 
respondían del todo al diagnóstico general que para las economías con problemas de balanza de pagos recomienda el organismo, la economía se contrajo dramáticamente en 1998, ya que el déficit público no era el causante de la devaluación, así como tampoco lo era la obligación de aplicar reformas estructurales y no únicamente de corte monetario o fiscal, en un país que poseía poca inclinación hacia el clientelismo y la corrupción (Krugman 1999).

De esta manera, con un diagnóstico y recetas inadecuadas en lo general, la economía tailandesa sufrió una contracción histórica en 1998, que únicamente se reactivó cuando los mercados se estabilizaron y volvió la confianza en 1999 y 2000 , no como producto de las medidas de política económica seguidas, sino de la tendencia natural de la economía a resurgir después de un colapso y, por lo tanto, a presentar recuperaciones espectaculares, pero que en relación con el nivel económico y social registrado previo al estallido de la crisis, son menores en términos reales a aquellos o, cuando mucho, semejantes a las magnitudes registradas antes del período de la crisis económica.

La interrogante aquí es ¿en qué grado pueden tener relevancia las medidas aplicadas en común acuerdo con el FMI una vez que la economía se ha reactivado? O, dicho de otra manera, ¿se podrá mantener la reactivación económica bajo el esquema actual de política económica recesiva?

Si consideramos como válido nuestro argumento del acelerador, entonces podemos suponer que los niveles registrados entre 1999-2001 por las principales variables macroeconómicas de Tailandia no son producto directo del ajuste-reforma, sino resultado de la tendencia natural de la economía a crecer una vez que ha tocado fondo, lo que se conoce como el principio de aceleración, explicado en cualquier libro de texto de economía. Siempre sus resultados son espectaculares al principio, pero de magnitud real menor a la previa, y más aún, los efectos secundarios se vuelven de primer orden a grado tal de reducir las tasas de crecimiento de la economía a niveles menores a los registrados antes del estallido de la crisis económica. Dichos efectos secundarios tendrán un efecto contraccionista sobre las importaciones, más por la modificación cambiaria que por la recuperación de la competitividad de las exportaciones. De hecho, éstas tienen la función de generar un saldo favorable, debido al encarecimiento de las importaciones.

Los excedentes generados en la cuenta corriente tienen la finalidad de financiar parte de la deuda externa e interna y de reposicionar al sector manufacturero como el pivote de la economía.

En general, el cuadro resultante relacionado con las medidas de ajuste restituyó la confianza de la comunidad internacional, toda vez que Tailandia se comprometió a aplicar las recetas fondomonetaristas: se retomó el crecimiento, aunque acotado por los equilibrios fiscales $y$ monetarios; se comprometió a someter la economía al escrutinio de la economía internacional y del FMI, en particular. Las reservas se restablecieron; desaparecieron los déficits fiscales y de cuenta corriente; el tipo de cambio se estabilizó, después de la ola especulativa, con un valor superior al del período previo a la crisis; la demanda interna (consumo más inversión) se contrajo, particularmente la inversión (cuadro 2).

Así, la economía en general mostró signos de recuperación, pero surgieron desequilibrios fundamentales en los mercados laborales y en la distribución del ingreso, que permiten vislumbrar una reaparición de la 
La recuperación económica poscrisis en Tailandia

Cuadro 2

Comportamiento de la economía tailandesa 1998-2001

\begin{tabular}{lrrrr}
\hline Rubro & 1998 & 1999 & 2000 & 2001 \\
PIB & -10.8 & 4.2 & 4.2 & $3.0^{*}$ \\
Consumo & -9.5 & 3.5 & 5.2 & n.d. \\
Inversión & -45.1 & -4 & 5 & n.d. \\
Tipo de cambio & 41.3 & 37.84 & 43.09 & $43.9^{*}$ \\
Tasas de interés & 12.5 & 8.4 & 8.1 & $7.6^{*}$ \\
Déficit comercial (\% del PIB) & 12.8 & 10.2 & 7.5 & $6.0^{*}$ \\
$\quad$ Exportaciones & 52.9 & 56.8 & 68.2 & n.d. \\
$\quad$ Importaciones & 40.6 & 47.5 & 61.8 & n.d. \\
Empleo & 30.27 & 30.84 & 31.45 & $31.60^{*}$ \\
Reservas internacionales & 29.5 & 34.8 & 32.7 & $32.3^{*}$ \\
PIB per cápita & 75,627 & 74,675 & 71,550 & n.d. \\
Deuda externa total & 105.1 & 95.6 & 82 & n.d. \\
$\quad$ Deuda externa (\% PIB) & 93.9 & 78.4 & 66.3 & n.d \\
Salario mínimo** & 162 & 162 & 162 & 165 \\
$\quad *$ Estimado. & \\
$\quad$ ** Para Bangkok y las provincias de Samut Prakan, Nonthaburi, Pathum Thani, Nakhon Athom, & \\
$\quad$ Samut Sakhon y Phuket. & & & &
\end{tabular}

pobreza y, de manera global, una caída del bienestar económico-social que se había logrado, particularmente desde mediados de la década de los ochenta.

En efecto, si desagregamos un tanto la información de empleo e ingreso salarial, observamos que la población económicamente activa PEA (que es alrededor de 52 por ciento de la población total), es la que está cargando con el peso principal de la recuperación económica. El empleo ha disminuido en estos tres años y meses y solo alcanzará niveles semejantes a 1997 a fines del 2000 (ver cuadros) y, si consideramos que la PEA se ha incrementado en 4.8 por ciento (pasó de 31,82 a 33,41 millones) en el período 1994-2000 (o sea 1590 trabajadores), entonces el desempleo ha resurgido y pasado de 830000 a un 1000400 desplazados, sin contar el desempleo estacional, que se mantiene en alrededor de 2.4 por ciento de la PEA para el período de análisis.
El salario, por su parte, se ha estancado en alrededor de cuatro dólares diarios, en términos promedio, para permitir a las exportaciones generar los excedentes en divisas, cumplir con los compromisos con el exterior y reactivar a la economía con base en el sector exportador (ver los cuadros 1 y 2 ).

\section{Conclusiones}

En este breve artículo hemos propuesto un punto de vista alterno respecto a los factores que explican la incipiente recuperación de la economía tailandesa de los últimos años, ${ }^{5}$ pero, sobre todo de los efectos inmediatos y directos de las políticas económicas anticrisis aplicadas por Tailandia a partir del estallido de la crisis financiera en 1997.

Hemos argumentado que dichas medidas de política económica no correspondían del todo a los síntomas que estaba presentando la economía tailandesa, pues las características del 
estallido de dicha crisis no se asemejaban totalmente a los diagnósticos de los que parte el FMI como principio de fe para atender los problemas de desequilibrio externo y ataque especulativo.

Aún más, hemos demostrado que los efectos sociales de dichas medidas de política económica han afectado al bienestar social y que, contradictoriamente a los supuestos que espera el FMI, la economía tailandesa se ha recuperado por el detonante del principio de aceleración. Además, es de esperar que este principio sea insuficiente para garantizar la recuperación del crecimiento económico a tasas similares a las reportadas por Tailandia, cuando menos en las dos últimas décadas, previas al estallido de la crisis. Por el contrario, es posible que el deterioro del bienestar sólo se encuentre en su fase inicial, lo que acentuaría y reforzaría la posibilidad de algunos disturbios sociales.

La tarea del gobierno tailandés será, por lo tanto, recuperar los principios fundamentales de su modelo de desarrollo, que supeditó el crecimiento económico al desarrollo de la sociedad (en ese sentido, sería interesante analizar las políticas sociales anticrisis desarrolladas por Tailandia en estos cuatro años). De otra manera, Tailandia se convertirá en una réplica más de las tristemente célebres economías latinoamericanas que aún se encuentran inmersas en las reformas estructurales de segunda generación, las cuales hasta ahora solo han demostrado ser eficientes para el crecimiento económico con inclusión social.

\section{Fuentes}

Robins, Fred (2000). "Asia's 1997 Crash: its Caracter, Causes and Consequences" en Frank-Jurgen Richter. The East Asian Development Model (Economic Growth, Institutional Failure and the Aftermath of the Crisis, pp. 17-52. McMillan, Great Britain; González y Segura (2001) La crisis financiera asiática. Una explicación no ortodoxa (mimeo); FMI (1998). "The Asian crisis: causes and cures", Finance and Development, vol. 35, Banco Mundial (1998). East Asia: The Road to Recovery. World Bank, Washington D.C.; Krugman, Paul (1999) De vuelta a la economía de la Gran Depresión. Norma, Colombia; Hock-Bean Cheah (2000) "The Asian Economic Crisis: Three perspectives on the Unfolding of the Crisis in the Global Economy". en Frank-Jurgen Richter. The East Asian Development Model
(Economic Growth, Institutional Failure and the Aftermath of the Crisis). McMillan, Great Britain, pp. 97-116; Limskul, Kitti (1999) "The Financial and Economic Crisis in Thailand: Policy Responses, Social Impact and Counter Measures", en Tran Van Hoa. The Asia Crisis. The Cure, their Effectiviness and the Prospects After. MacMillan Press, Great Britain, pp.19-63; Asian Development Bank (1999). Asian Development Outlook 1999; Banco Mundial (1998). La hora de la reforma institucional. World Bank,Washington D.C.; Williams Spiegel, Henry (1991). The Growth of Economic Thought. Duke University Press, USA; Imudom, Warangkana (2000). The role of minimum wage in Thailand. Bank of Thailand; FMI (1999) Occasional Papers. IFM-Supported Programs in Indonesia, Korea, and Thailand: A preliminary Assessment (Timithy Lane et al.), Washington, D.C.; ----(2000). Thailand. Country Report. No. 00/20. Washington, D.C.; ----- (2000). IMF Concludes Post-Program Monitoring Discussion on Thailand, en: http:www.imf.org/external/np/2000/; Bank of Thailand (1999) Report Annual. Group on Monetary Policy, Bangkok.

\section{Notas}

${ }^{1}$ Como argumentó el Fondo Monetario Internacional en junio de 2000 en el estudio denominado "Recuperación tras la crisis asiática y papel del FMI" (2000).

${ }^{2}$ Dicho principio, cuya paternidad se otorga a J.M. Clarck, establece que, los cambios en el consumo o la producción, llevarán a magnificar los cambios en la inversión, es decir, es un principio similar al multiplicador keynesiano (ver: William Spiegel 1991: The Growth of Economic Thought).

${ }^{3}$ Únicamente enlistaremos algunas de las principales medidas del programa de ajuste, no las analizaremos, pues el objetivo de este artículo es ver algunos de los efectos de estas medidas y no las medidas en sí. Además de que existe bastante literatura al respecto.

${ }^{4}$ FMI (2001). Causes and Implications of the Financial Crisis in Asia, p. 2

${ }^{5}$ Véase por ejemplo: FMI (2000). Recuperación tras la crisis asiática y papel del FMI. Documento 00/05(S), junio de 2000, 22 p. 